\title{
SHELF-LIFE PREDICTION MODEL OF CHITOSAN COATED EGGS AT DIFFERENT STORAGE TEMPERATURES
}

\author{
- Research paper - \\ Yunfeng HU, Liping ZHANG, Jinjin WEI, Zengyu WEI \\ College of Food Engineering and Biotechnology, Tianjin University of Science and Technology, \\ Tianjin 300457, China
}

\begin{abstract}
In order to study the quality changes and shelf life of chitosan coated eggs during storage, the quality, gas chamber diameter, yolk coefficient and the quality change of Hough unit during storage were measured at temperature of 5,20 and $35^{\circ} \mathrm{C}$. The Pearson correlation between the quality indexes and the egg Hough's unit value was analyzed, and the yolk coefficient was analyzed dynamically and the shelf life prediction model was based on the basis of the Arrhenius equation. The results showed that the quality of eggs, egg yolk coefficient, and Huff units all decreased with the extension of storage time, and the diameter of the air chambers of eggs showed an increasing trend with the extension of storage time. Moreover, the storage environment at high temperature $\left(20\right.$ and $\left.35^{\circ} \mathrm{C}\right)$ had a significant effect on the quality deterioration than the low temperature $\left(5^{\circ} \mathrm{C}\right)$ storage environment; The correlation coefficient between egg yolk coefficient and Hough unit is the highest at all temperatures, which can be used as an important indicator for shelf life prediction; According to the changing rule of egg quality, the yolk coefficient can establish a first order kinetic model. According to the model established by the egg yolk coefficient, the coefficient $\mathrm{R}^{2}$ of the fitting curve of the predicted value and the measured value is 0.9825 , and the average relative error $\mathrm{P}$ is $9.32 \%$ and less than $10 \%$. The kinetic relationship between yolk coefficient and temperature is well described. At the same time, based on the dynamic model, the shelf life prediction model of chitosan-coated eggs based on yolk coefficient was determined by the dynamic model. The average relative error was $7.6 \%$, less than $10 \%$, which indicated that the egg shelf life prediction model based on the change of egg yolk coefficient was feasible.
\end{abstract}

Keywords: Chitosan; eggs; dynamic model; Shelf life model

\section{INTRODUCTION}

Egg is an important source of animal protein, which contains a lot of fat, minerals, vitamins, lecithin, betaine, zeaxanthin, lutein and so on. It is deeply loved by the majority of consumers (Drewnowski, 1995; Yang et al., 2018; Fu et al., 2011). The egg is a living substance susceptible to microbial spoilage during storage and transport (Xue et al., 2017). Egg coating technology is a method to prolong the storage life of the egg (Liang et al., 2018). Chitosan is the most widely studied polysaccharide natural polymer. Because of its good film forming, gas barrier and unique antibacterial properties, it has a wide range of sources, so it has been widely studied in the preservation of egg film (Liu et al., 2009; Tezotto-Uliana et al., 2014). Some experts have studied the quality changes of uncoated and chitosan-coated eggs and the effects of different coating treatments on the shelf life of eggs (Caner, 2008; Scott, 2000; Wang, 2018; Hu, et al., 2019).

In recent years, domestic and foreign scholars have used dynamic models to study the quality changes of meat products, vegetables, fruits and so on, and predict their storage period, which has achieved good results ( $\mathrm{Lu}$, et al., 2014). Singh and Ma respectively studied the investigation of cellulosic packets impregnated with silver nanoparticles for enhancing shelf-life of vegetables and the shelf life extension technologies of fresh-cut fruits and vegetables (Singh et al., 2017; Ma et al., 2017). Faucitano studied the shelf life of pork from five different quality classes (Faucitano et al., 2010). Deng and Aday respectively studied the egg shelf life evaluation and strawberry

${ }^{1}$ Corresponding author. E-Mail address: hu-yf@163.com 
shelf-life, all of which have important reference values (Deng et al., 2018; Aday et al., 2013). However, there are few studies on the shelf life model of eggs during storage, only the model based on regression equation fitting (Zhang et al., 2011). In this study, the changes of the quality of chitosan-coated eggs are studied in terms of diameter, mass, egg yolk coefficient, and Hough unit at different temperatures. The

\section{MATERIALS AND METHODS}

Materials: fresh eggs were obtained from Moor Lake Chicken Farm (Tianjin, China). Chitosan was produced by Jincheng Biotechnology Co., Ltd (Henan, China). Glycerin was produced by the chemical reagents factory (Tianjin, China). Glacial acetic acid was produced by Tianjin Fengchuan Chemical Reagent Technology Co., Ltd. All chemical reagents were of analytical grade.

Devices: Weight of eggs during storage was measured by electronic analytical balance (PL203/01, Shanghai, China). The chamber diameter of eggs during storage was measured by vernier calipers (Tianjin, China). A magnetic stirrer was used to stir chitosan solution (78-1, Jiangnan, China). An egg lamp was used for lighting. The $\mathrm{pH}$ value was measured with a $\mathrm{pH}$ meter (MP522, Shanghai, China). Intelligent mould incubator was used to cultivate chitosan-coated eggs (MHP-250, Shanghai, China).

Experimental treatment: 2\% chitosan solution was used to coat the eggs (Chen, 2010). The coated eggs were stored at 5,20 and $35{ }^{\circ} \mathrm{C}$, respectively, and the treatment was recorded as 0 days. The eggs were measured on the 0 th, 5 th, 11th, 15th, 21st, 27th, 32th, 41st, and 54th days respectively. Each time 10 eggs were measured and their average value was taken. Three parallel experiments were conducted for each result. Changes in egg quality during storage: Each of the 10 eggs was weighed with an accuracy of $0.001 \mathrm{~g}$ electronic balance.

Change in diameter of air chamber during egg storage: The diameter of the largest part of the egg gas chamber of different storage conditions was measured with the egg lamp from the small end of the egg. The average value of 10 eggs was measured each time (Zhao et al., 2004).

Changes of egg yolk coefficient during the storage of eggs: The contents of egg yolk were measured with $0.2 \mathrm{~mm}$ vernier calipers and the
Arrhenius equation is used to establish a mathematical model for the quality change of these chitosan coated eggs and the storage temperature and time. The cost of the model established for the prediction of the shelf life of chitosan coated eggs was low. It can be used as a broad prediction method to know the remaining shelf life of chitosan coated eggs.

height of egg yolk was measured with a vernier caliper with a precision of 0.2 . The average diameter of yolk diameter (the line between yolk and yolk between yellow and white) was measured, and the average value of 10 eggs was taken (Yu et al., 2012).

Egg yolk coefficient $=$ yolk height $(\mathrm{cm} / \mathrm{egg}$ yolk diameter $(\mathrm{cm})$

Change of Hough unit during the storage of eggs: According to the regression relationship between egg quality and protein height, the height of egg concentrated protein was measured with $0.2 \mathrm{~mm}$ vernier caliper first, then Hough unit value was calculated according to equation 2:

$H u=100 \log \left(H+7.57-1.7 W^{0.37}\right)$

where $\mathrm{Hu}-\mathrm{Hough}$ unit value of eggs; $\mathrm{H}-$ Concentration of concentrated protein $(\mathrm{mm})$; W- Egg quality $(\mathrm{g})$.

Determination of reaction rate constants $\mathrm{K}$ and determinate ratio $\mathrm{R}^{2}$ : The correlation analysis between physical and chemical indexes and Huff unit value was carried out to determine the best quality indicators related to Huff unit value.

Zero-order reaction model equation: $y=y_{0}-k t$

First-order reaction model equation is: Iny $=$ In $y_{0}+k t$

Arrhenius equation determining A and Ea: The yolk coefficient of chitosan-coated eggs can be obtained at 5,20 and $35^{\circ} \mathrm{C}$ storage conditions. The Arrhenius equation of the reaction was obtained by plotting the reaction order and calculating the reaction constant (AN et al., 2006; Ma et al., 2012).

$\ln k=\ln A-\frac{E a}{R T}$

Dynamics Prediction Model: Combining with Arrhenius equation, the first-order dynamic prediction model of yolk coefficient was deduced as follows (Fu et al., 2016). 
First-order dynamic prediction model:

$y=y_{0} \exp \left[A \exp \left(\frac{-E a}{R T}\right) t\right]$

Verification of dynamic model: The model is verified by comparing the average relative percentage error (Ketelaere et al., 2003; Boquet., 1978). Calculation formula is (7):

$$
p=\frac{1}{N} \sum_{i=1}^{N} \frac{\left|V_{e}-V_{p}\right|}{V_{e}} \times 100 \%
$$

In equation $7, V_{e}$ and $V_{p}$ are measured values and predicted values for each test, respectively; $\mathrm{N}$ is the number of tests, and when the mean value of $\mathrm{P}$ is less than $10 \%$, it is considered to be established. The quality model conforms to dynamic changes.

Establishment and Verification of Shelf Life Prediction Model: Based on the dynamic

\section{RESULTS AND DICUSSIONS}

The relationship between changes of weight of chitosan-coated eggs and storage time under different storage temperatures

As indicated in Figure 1, the weight of the chitosan-coated eggs decreased significantly with the prolongation of storage time, and the rate of decline in weight increased with increasing temperature.

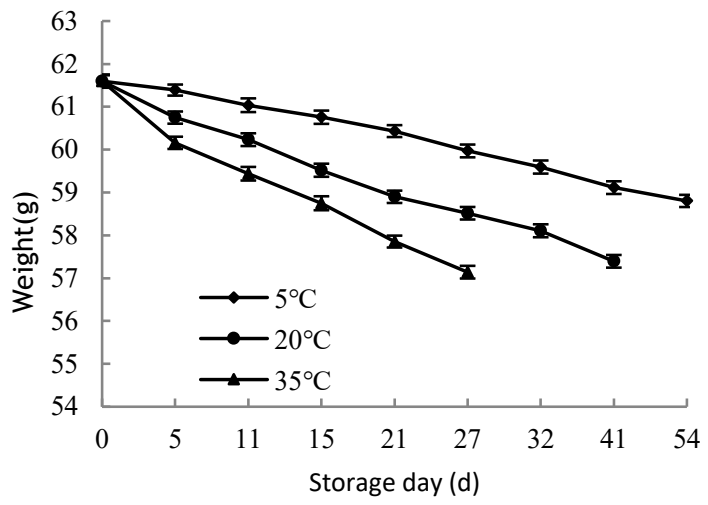

Figure 1. The change in weight of chitosan-coated eggs with different storage temperatures

When stored at $35^{\circ} \mathrm{C}$ for 27 days, the weight of the chitosan-coated eggs dropped by $7.1 \%$. The weight of eggs stored at $5{ }^{\circ} \mathrm{C}$ and $20{ }^{\circ} \mathrm{C}$ decreased by $2.1 \%$ and $5.2 \%$ on the 27 th day, respectively. Especially for eggs stored at $5{ }^{\circ} \mathrm{C}$, the weight decreased by $4.6 \%$ when stored on the 54th day, which is obviously better than the eggs under high temperature storage. This was similar to the weight change of uncoated eggs. The weight loss of uncoated eggs was smaller prediction model, the shelf-life prediction model of egg coated with egg yolk coefficient was established. The feasibility of the shelf-life prediction model is verified based on the average percentage relative error.

Shelf life model equation is (8):

$S L=\frac{F_{t}}{A \exp (-E a / R T)}$

where SL is for Shelf life, $\mathrm{d} ; F_{t}$ is correspond to the physical and chemical indexes at the end of the shelf life of eggs; $\mathrm{T}$ is for storage temperature, $\mathrm{K}$.

Data processing: Using Excel to do data collation and related data fitting and calculation, SPSS statistical software was used to analyze the correlation and verify the rationality of the model.

at $5^{\circ} \mathrm{C}$, while the weight loss rate increased significantly at $20^{\circ} \mathrm{C}$ and $35^{\circ} \mathrm{C}$. After 30 days storage at $35{ }^{\circ} \mathrm{C}$, the weight of eggs decreased by about $22 \%$ (Yu et al., 2012). This indicated that low temperature can delay the loss of internal water in eggs and the rot of eggs (Jin et al., 2011; Liu et al., 2011). In addition, the decrease of weight was also related to the shell membrane, the porosity of eggshell and the thickness of eggshell (King'ori, 2011).

The relationship between the change of diameter of chitosan coated egg chamber and storage time under different storage temperature

It can be seen from Figure 2 that the air chamber diameter of eggs increased with the prolongation of storage time. The higher the storage temperature was, the faster the increase rate of chamber diameter was. When stored at 27 days, the air chamber diameter of eggs increased by $57 \%$ and increased faster at $35^{\circ} \mathrm{C}$. Stored at $20^{\circ} \mathrm{C}$ for 27 days, the air chamber diameter increased by $33.3 \%$. When stored at 54 days, the air chamber diameter increased by $11.9 \%$ at $5^{\circ} \mathrm{C}$, which was significantly lower than those of eggs stored at high temperature. Those indicated that low temperature can increase the diameter of the buffer chamber. This was consistent with the change of chamber height of uncoated eggs. As the temperature and time increase, the height of the chamber increases. 


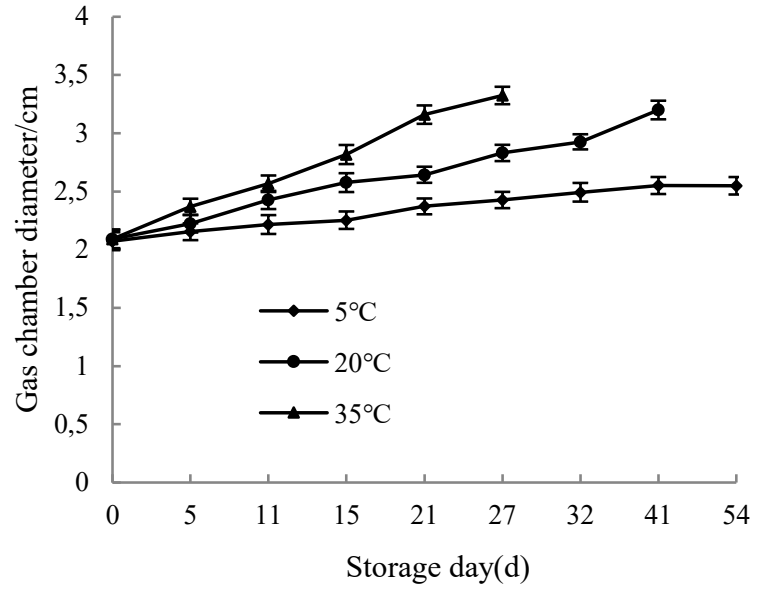

Figure 2. The change in air chamber diameter of chitosan-coated eggs at different storage temperatures

Stored at $35 \mathrm{C}$ for 30 days, the chamber height of uncoated eggs increased from $2.0 \mathrm{~mm}$ to $15.0 \mathrm{~mm}$ (Yu et al., 2012). This may be due to the evaporation of water in the eggs with the prolongation of storage time, which makes the volume of the contents of the eggs smaller and the volume of the air chamber larger.

\section{Effects of storage temperature on egg yolk coefficient and storage time of chitosan coated eggs}

As Figure 3 shows, high temperature accelerated the reduction of yolk coefficient. When the eggs were stored at $35^{\circ} \mathrm{C}$ for 27 days, the yolk coefficient decreased by $76.5 \%$, and the eggs were all yellowed, reaching the end of the shelf life. At this time, the egg yolk coefficient at $20^{\circ} \mathrm{C}$ reduced by $51 \%$, and only a small part of the eggs appeared yellow scattered phenomenon.

When the eggs were stored at $5{ }^{\circ} \mathrm{C}$ for $54 \mathrm{~d}$, the yolk coefficient decreased by $21.6 \%$, which was significantly lower than those eggs stored at high temperature for 27 days. The yolk coefficient of uncoated eggs was decreased by about $82.4 \%$ after 30 days storage at $35^{\circ} \mathrm{C}$. Those can be concluded that low temperature storage and chitosan coating can delay the decrease of eggs yolk coefficient.

The relationship between storage time and change of Hough unit in chitosan coating at different storage temperatures

As showed in Figure 4, as the storage time was extended, the Huff unit of the egg gradually decreased. The higher the storage temperature, the faster the Huff unit fell.

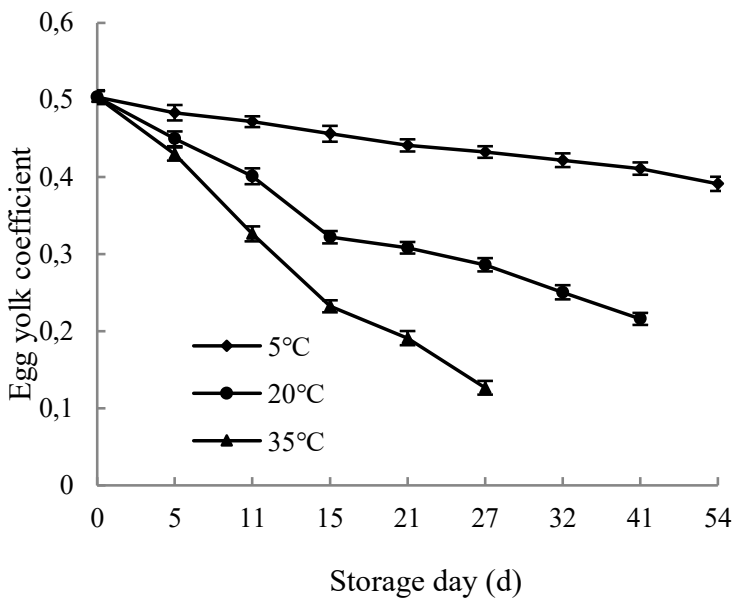

Figure 3. The change in yolk index of chitosan-coated eggs with different storage temperatures

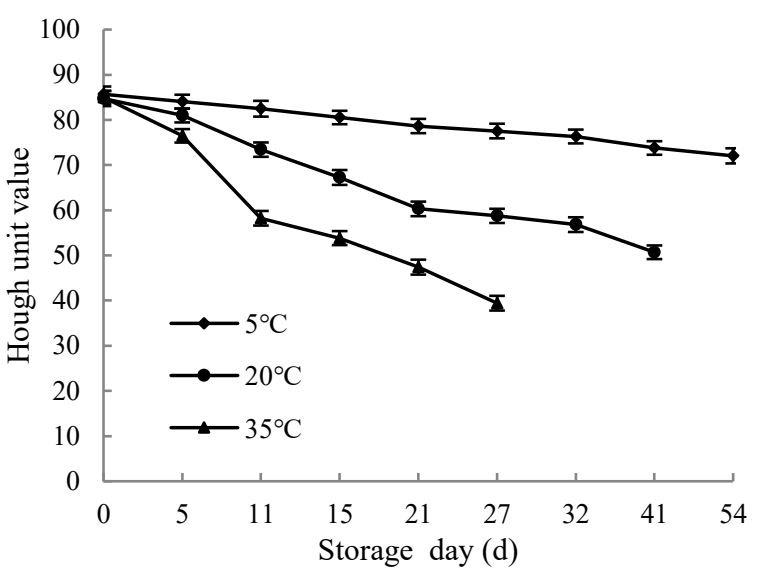

Figure 4. The change in Hough unit of chitosan-coated eggs with different storage temperatures

When the coated eggs are stored at $35{ }^{\circ} \mathrm{C}$ for 27 days, the Huff unit value is reduced by $44.5 \%$, and when stored at $20^{\circ} \mathrm{C}$ and $5{ }^{\circ} \mathrm{C}$ for 41 days, the Huff unit values were 51 and 72 .

When the storage period reached 54 days, the eggs of the Huff unit were decreased by $16 \%$. However, the Huff unit values of the eggs in the uncoated group were decreased by $49.3 \%$ after 11 days storage at $25^{\circ} \mathrm{C}$. This can be explained by that with the prolongation of storage time, microorganisms grow and reproduce inside eggs through eggshell stomata and proteins are decomposed, resulting in water-like proteins, which resulted in the reduction of the Huff unit value. Chitosan-coated eggs blocked the eggshell stomata, hindered the entry of microorganisms and delayed protein deterioration (Ji et al., 2018). 
When the coated eggs are stored at $35{ }^{\circ} \mathrm{C}$ for 27 days, the Huff unit value is reduced by $44.5 \%$, and when stored at $20^{\circ} \mathrm{C}$ and $5{ }^{\circ} \mathrm{C}$ for 41 days, the Huff unit values were 51 and 72 .

\section{The correlation between Hough units and} various indicators

The Hough unit value is the index of the inspection and expression of egg freshness stipulated by the US Department of agriculture's egg standard, which represents the quality of protein (Caner, 2005) The Hough unit value of the egg has a certain relationship with those and can be expressed by the Pearson correlation coefficient $r$. When $r>0.9$, it can be considered that the correlation is significant. According to Table 1, the Pearson coefficient of weight, air chamber diameter and yolk coefficient were more significant at different temperatures, and the sigma $|\mathrm{r}|$ is $2.965,2.939$ and 2.975 respectively.

The Pearson system of egg yolk coefficient was the highest, the weight was the second, and the measurement of the egg yolk coefficient was both simple and fast and no chemical pollution in determining the remaining life of the shelf life. Therefore, the yolk coefficient can be used as the most relevant index to predict the shelf life of eggs.

Table 1. Pearson correlation coefficient among the various indicators and Haugh

\begin{tabular}{lllll}
\hline & $5^{\circ} \mathrm{C}$ & $20^{\circ} \mathrm{C}$ & $35^{\circ} \mathrm{C}$ & $\sum|\mathrm{r}|$ \\
\hline Quality & $0.997^{* *}$ & $0.989 * *$ & $0.979 * *$ & 2.965 \\
Gas chamber diameter & $0.992^{* *}$ & $0.978^{* *}$ & $0.969^{* *}$ & 2.939 \\
Egg yolk coefficient & $0.996^{* *}$ & $0.989 * *$ & $0.990^{* *}$ & 2.975 \\
\hline
\end{tabular}

Note: $* *$ is significantly correlated at 0.01 level (bilateral).

\section{Establishment of a dynamic model for egg} quality of chitosan coated eggs

The result showed that the sum of the determination coefficient of the first-order kinetic model of the egg yolk coefficient was 2.9036, which was greater than the determination coefficient of 2.8047 of the zero-order kinetic model. Therefore, the yolk coefficient was selected by the first-order kinetic model. The larger $\mathrm{R}^{2}$ indicated a better overall linear relationship. It was known from the table that the coefficient of the regression equation of the yolk coefficient at different storage temperatures was more than 0.9, indicating that the regression equation has a higher fitting precision.
The activation energy of the egg yolk coefficient of chitosan coated eggs under different temperature conditions was calculated by the Arrhenius equation. The activation energy of the egg yolk coefficient was $5.32 *$ $10^{4} \mathrm{KJ} / \mathrm{mol}$ and the A value was $5.65 * 10^{7}$. The kinetic prediction model of the yolk coefficient was obtained by the equation 6 .

Prediction model equation of egg yolk coefficient:

$$
Y I_{t}=Y I_{0} \exp \left[\left(-5.65 \times 10^{7} \exp \left(\frac{-6404.8}{T}\right)\right) t\right]
$$

where $Y I_{t}$ : Yolk values of eggs stored at $\mathrm{t}$ time; $Y I_{0}$ : Initial egg yolk system value

Table 2. Reaction rate constant $\mathrm{k}$ and determination coefficient $\mathrm{R}^{2}$ of determination for zero and first order regression

\begin{tabular}{cccccc}
\hline & & \multicolumn{2}{c}{ Zero order } & \multicolumn{2}{c}{ First order } \\
\cline { 3 - 6 } Index & Temperature $\left({ }^{\circ} \mathrm{C}\right)$ & Rate constant & Decisive factor & Rate constant & Decisive factor \\
& & $\mathrm{k}$ & $\mathrm{R}^{2}$ & $\mathrm{k}$ & $\mathrm{R}^{2}$ \\
Egg yolk & 5 & 0.0024 & 0.9282 & 0.0052 & 0.9544 \\
coefficient & 20 & 0.008 & 0.9058 & 0.0218 & 0.9688 \\
& 35 & 0.015 & 0.9707 & 0.0485 & 0.9804 \\
$\mathrm{R}^{2}$ & & & 2.8047 & & 2.9036 \\
\hline
\end{tabular}

Note: the regression coefficient of the equation is greater than 0.9 , indicating that the equation is very significant. 
Verification of the prediction model of chitosan coated eggs

The egg yolk coefficient at $25{ }^{\circ} \mathrm{C}$ in the validation group was calculated by using the egg yolk coefficient prediction model equation, which was the predicted value and compared with the measured value. The results showed that the predicted and measured values of the yolk coefficient calculated by equation 9 are based on the coefficient of determination of the 1:1 line being 0.9596 , and the average relative error P calculated from equation 7 was $9.32 \%$, which was less than $10 \%$, indicating that the model can better prediction of egg yolk coefficient at $5 \sim 35^{\circ} \mathrm{C}$.

\section{Establishment of Shelf-life Prediction Model for Chitosan-coated Eggs}

Based on the above theories and experimental results, it was determined that the change in the yolk coefficient was used to predict the shelf life, and the equation for the shelf life prediction model was derived from the simplified equation 10 :

$S L_{(Y I)}=\frac{\ln \left(Y I_{t}\right)-\ln \left(Y I_{0}\right)}{A \exp \left(-\frac{E a}{R T}\right)}$

\section{CONCLUSION}

In this paper, the changes of the quality of chitosan-coated eggs, the diameter of the air chamber, the yolk coefficient, and the Huff unit values were studied under different storage temperatures. The results showed that the egg quality, egg yolk coefficient and Huff unit values decreased with the prolongation of storage time, while the diameter of egg gas chamber increased with the prolongation of
$S L_{(Y I)}$ : Shelf life, d; $\mathrm{YI}_{0}$ : The initial value of the egg yolk coefficient; $Y I_{t}$ : Egg yolk coefficient values for eggs stored for $\mathrm{t}$ days; $R$ : Gas constant, $8.314 \mathrm{~J} /(\mathrm{mol} \cdot \mathrm{K}) ; \quad T$ : Storage temperature (Kelvin), $\mathrm{K}$.

The parameter values obtained by calculation were substituted into equation 10 , and the equation for predicting the shelf life of eggs in chitosan coating circulation was deduced:

$$
S L_{(Y I)}=\frac{\ln \left(Y I_{t}\right)-\ln \left(Y I_{0}\right)}{-5.65 \times 10^{7} \exp \left(-\frac{6404.8}{T}\right)}
$$

\section{Establishment of Shelf-life Prediction Model for Chitosan-coated Eggs}

According to prediction model equation 6 , the shelf life value of chitosan coated eggs at $25^{\circ} \mathrm{C}$ in the validation group was calculated, which was shelf life prediction value. Comparing the predicted value with the measured value, it was found that the absolute value of the relative error between the prediction value and the measured value of chitosan coating stored at $25{ }^{\circ} \mathrm{C}$ was $7.6 \%$, less than $10 \%$. Therefore, according to the above theory, the prediction model of shelf life can be used to predict shelf life of chitosan-coated eggs under storage conditions of 5 to $35^{\circ} \mathrm{C}$.

storage time. According to Pearson correlation analysis of each quality index and Huff unit value of eggs, yolk coefficient can be used as the most relevant index to predict the shelf life of eggs. According to the variation law of egg quality, the first-order dynamic model and Arrhenius equation of yolk coefficient have good fitness. The shelf life prediction model of yolk coefficient was established by using the equation.

\section{REFERENCES}

1. Drewnowski, A. (1995). Energy intake and sensory properties of food. American Journal of Clinical Nutrition, 62( 5 Suppl): 1081S - 1085S.

2. Yang, X, L., Li, W, Y., Wei, S, N., Zhang, J, B. (2018). Effects of Different Storage Temperatures on Nutritional Composition of Eggs. Aquaculture and Feed, (08): 20-21.

3. Fu, G, C., Luo, Y, W., Wen, C., Wang, L, C. (2011). Effects of different betaine products on laying hens'performance and egg quality. Heilongjiang Animal Husbandry and Veterinary Medicine, (21): 71-72.

4. Xue, Y, R., Mao, W., Zhao, R, S., Wang, C., Liu, B. (2017). Study on the Changes of Microorganisms and Egg Quality in the Storage of Eggs. Animal Husbandry and Feed Science, 38(08):67-69+72. 
5. Liang, X, T., Yang, L, J., Ye, L., Luo, W, J., Zhao, Y, W., Wang, Z. (2018). A Brief Talk on Egg Coating Preservation Technology. Jiangxi Journal of Animal Husbandry and Veterinary Medicine, (05): 4-6.

6. Liu, X, D., Jang, A., Kim, D, H. (2009). Effect of combination of chitosan coating and irradiation on physicochemical and functional properties of chicken egg during room-temperature storage. Radiation Physics \& Chemistry, 78(7): 589-591.

7. Tezotto-Uliana, J, V., Fargoni, G, P., Geerdink, G, M., \& Kluge, R, A., (2014). Chitosan applications pre- or postharvest prolong raspberry shelf-life quality. Postharvest Biology and Technology, 91, 72-77.

8. Caner, C, Özge, Cansiz. (2008). Chitosan coating minimises eggshell breakage and improves egg quality. Journal of the Science of Food \& Agriculture, 88(1): 56-61.

9. Scott, T, A. Silversides, F, G. (2000). The effect of storage and strain of hen on egg quality. Poultry Science, 79(12): 1725-1729.

10. Wang, J. (2018). The effect of chitosan/nano-silver coating on the egg preservation. Food and Machinery, 34(01):110-116.

11. Hu, Y, F., Zhang, L, P., Wei, J, J., Wei, Z, Y., Chen, J, R. (2019). Dynamic Model of Quality Change of Eggs Coated with Chitosan. Science \& Technology of Food Industry, 40(01):87-91.

12. Lu, Q., Liviu, Giurgiulescu. (2014). Property Prediction of Dry Common Carp (Cyprinus Carpio) During Storage by Kinetic Model. Acta Universitatis Cibiniensis. Series E: Food Technology, 18(02): 55-64.

13. Singh, M., Saharren, T., Singh, M. (2017). Investigation of cellulosic packets impregnated with silver nanoparticles for enhancing shelf-life of vegetables. LWT- Food Science and Technology, 86.

14. Ma, L., Zhang, M., Bhandari, B. (2017). Recent developments in novel shelf life extension technologies of fresh-cut fruits and vegetables. Trends in Food Science \& Technology, 64:23-38.

15. Faucitano, L., Ielo, M, C., Ster, C., et al.(2010). Shelf life of pork from five different quality classes. Meat Science, 84(3):466-469.

16. Deng, F., Chen, W., Wang, J. (2018). Fabrication of a sensor Array Based on Quartz Crystal Microbalance and the Application in Egg Shelf Life Evaluation. Sensors \& Actuators B Chemical, 265.

17. Aday, M, S., Temizkan, R., Büyükcan, M, B. (2013). An innovative technique for extending shelf life of strawberry: Ultrasound. LWT - Food Science and Technology, 52(2):93-101.

18. Zhang, Y, H., et al. (2011). Study on the Law of Quality Change in Egg Logistics Process. Food Science and Technology, 36 (8): 50-53.

19. Wang, H., Sun, Q., L, L., Zhang, S, W., Duan, Y, Q., Lv, J, P. (2013).Establishment and Test of Prediction Model for UHT Milk Shelf Life. Scientia Agricultural Sinica .46 (03): 586-594.

20. Yang, M, Z., Wang, X, L. (2015). Shelf-life prediction of instant flavor rice through kinetic models. Journal of Harbin University of Commerce, 31(06):710-714.

21. Liu, X, D., Jang, A., Kim, D, H., et al. (2009). Effect of combination of chitosan coating and irradiation on physicochemical and functional properties of chicken egg during room-temperature storage. Radiation Physics \& Chemistry, 78(7): 589-591.

22. S. Bhale, H., K. No, W. Prinyawiwatkul., et al. (2003). Chitosan Coating Improves Shelf Life of Egg. Food Science and Technology, 68(7): 2378-2383.

23. Chen, C, X. (2010). Effect of chitosan coating on egg quality. Food Science and Technology, 31 (24): 453-456.

24. Zhao, L., Tu, K., Pan, L, Q. (2004). Effects of different treatments on preservation of green shell eggs. Science \& Technology of Food Industry, 25 (11):69-71.

25. Yu, B., Wang, X, B. (2012). Dynamic model of quality change during storage of eggs. Journal of Agricultural Engineering, 28 (15): 276-279.

26. An, J., Zhang, M., Lu, Q., et al. (2006).Effect of a prestorage treatment with 6-benzylaminopurine and modified atmosphere packaging storage on the respiration and quality of green asparagus spears. Journal of Food Engineering, 77(4):951-957.

27. Ma, Y., Xie J., Zhou R., et al. (2012). Dynamics of the quality changes of the puffer dark striped puffer at different freezing temperatures. Journal of China Agricultural University, 17 
(1):138-142.

28. Fu, D, D., Wang, Q, H. (2016). Hyperspectral detection model for egg freshness, pH value and viscosity. Food Science and Technology, 37 (22): 173-179.

29. Ketelaere, B, D., Vanhoutte, H., Baerdemaeker, J, D., et al. (2003). Parameter estimation and multivariable model building for the non-destructive on-line determination of eggshell strength. Journal of Sound \& Vibration, 266(3): 699-709.

30. Boquet, R., Chirife, I, H, A. (1978). Equations for fitting water sorption isotherms of foods evalution of various two-parameter models. Journal Food Technology, 13(3): 319-327.

31. Yu, B., Wang, X, B. (2012). Kinetics of quality change for eggs Storage .Transactions of the Chinese Society of Agricultural Engineering, 28(15):276-280.

32. Jin, Y, H., Lee, K, T., Lee, W, I., et al. (2011).Effects of storage temperature and time on the quality of eggs from laying hens at peak production. Asian-Australasian Journal of Animal Sciences, 24(2): 278-284.

33. Liu, M, Y., Lian, H, P., Ren, F, Z. (2011). Effect of Storage Temperature on Respiratory Intensity and Quality of Eggs. Food Science and Technology, 32(6): 270-274.

34. King'ori A M. (2011). Review of the factors that influence egg fertility and hatchabilty in poultry. International Journal of Poultry Science, 10(6): 483-492.

35. Ji, X, F., Yang, H., Wang, J, M., Xiao, Y, P., Yang, G, L., Wang, W., Li, R. (2018). Effects of Storage Environment on Freshness of Eggs and Establishment of Prediction Model for Shelf Life of Fresh Eggs .Quality and Safety of Agricultural Products, (02):59-65+74.

36. Caner, C. (2005). The effect of edible eggshell coatings on egg quality and consumer perception. Journal of the Science of Food and Agriculture, 85(1): 1897-1902. 